УДК 621.373.826; 621.9.048.7

\author{
Ю.Н. Кульчин, Н.Г. Галкин, А.И. Никитин, Е.П. Субботин,
}

А.А. Костянко, Д.С. Пивоваров, Д.С. Яцко

Институт автоматики и процессов управления ДВО РАН, Владивосток, Россия

\author{
ПРИМЕНЕНИЕ ВОЛОКОННЫХ ЛАЗЕРОВ \\ ДЛЯ ФОРМИРОВАНИЯ ПОКРЫТИЙ ИЗ ПОРОШКОВ \\ ПЕРЕХОДНЫХ И РЕДКОЗЕМЕЛЬНЫХ МЕТАЛЛОВ \\ В ПОСТОЯННОМ МАГНИТНОМ ПОЛЕ
}

\begin{abstract}
В работе представлены результаты исследования процессов формирования слоев из порошковых смесей $\mathrm{Sm}-\mathrm{Co}$ и Sm-Fe с использованием непрерывного лазерного излучения с длиной волны 1,07 мкм в присутствии постоянного магнитного поля, в защитной среде из инертных газовых смесей. Показано, что технологически возможно использовать энергию лазерного луча для формирования металлических сетчатых структур переменного состава с учетом локальности и быстротечности высокотемпературного процесса формирования доменных областей под воздействием на расплав внешнего постоянного магнитного поля.
\end{abstract}

Ключевые слова: волоконный лазер, порошки Sm-Co и Sm-Fe, магнитное поле.

Y.N. Kulchin, N.G. Galkin, A.I. Nikitin, E.P. Subbotin, A.A. Kostyanko, D.S. Pivovarov, D.S. latsko

Institute of Automation and Control Processes Far Eastern Branch of the Russian Academy of Sciences (IACP FEB RAS), Vladivostok, Russian Federation

\title{
APPLICATION OF THE FIBER LASERS FOR FORMATION OF COVERINGS FROM POWDERS OF TRANSITIONAL AND RARE-EARTH METALS IN CONSTANT MAGNETIC FIELD
}

The paper presents the results of the research of processes of the formation of layers from powder mixtures $\mathrm{Sm}-\mathrm{Co}$ and $\mathrm{Sm}-\mathrm{Fe}$ using continuous laser radiation of wavelength $1.07 \mu \mathrm{m}$ in the presence of a constant magnetic field in a protective medium from inert gas mixtures. It is shown that it is technologically possible to use the energy of laser beam to form metal mesh structures of variable composition, taking into account the locality and transience of the high-temperature process of formation of domain domains under the influence of an external constant magnetic field on the melt.

Keywords: fiber laser, Sm-Co and Sm-Fe powders, magnetic field. 
Теоретические и экспериментальные исследования способов формирования покрытий из переходных и редкоземельных металлов, например, системы Sm-Co и $\mathrm{Sm}-\mathrm{Fe}$, представляют особый интерес, поскольку такие материалы обладают высокой намагниченностью, высокой коэрцитивной силой, высокой температурой Кюри и внутренней коррозионной стойкостью. Традиционные способы выращивания эпитаксиальных тонких пленок $\mathrm{SmCo}_{5}[1,2,3]$ не являются технологичными и не позволяют в реальном времени формировать магнитные пленочные структуры различной конфигурации. Известные способы производства постоянных магнитов на основе $\mathrm{Sm}-\mathrm{Co}$ и $\mathrm{Sm}-\mathrm{Fe}$ с улучшенными магнитными характеристиками предполагают многоэтапный процесс, как правило, с применением энергии индукционных печей в среде инертных газов или в вакууме $[4,5]$. Особенностью технологии использования лазерного излучения на начальном этапе изготовления редкоземельных магнитов является локальность и быстротечность высокотемпературного процесса формирования доменной структуры под воздействием внешнего постоянного магнитного поля [6]. Однако работ по формированию ферромагнитных пленочных покрытий методом лазерной наплавки с использованием волоконных лазеров средней мощности не производилось, хотя эти исследования представляют значительный интерес как с фундаментальной, так и с прикладной точек зрения.

Целью настоящей работы явилось исследование процесса нанесения ферромагнитных пленочных покрытий на немагнитные подложки с использованием комбинированной установки «волоконный лазер - роботизированный комплекс» в присутствии постоянного магнитного поля.

Экспериментальные исследования процессов создания структур из порошкового материала $\mathrm{Sm}-\mathrm{Co}$ и $\mathrm{Sm}-\mathrm{Fe}$ проводились с использованием иттербиевого волоконного лазера ЛС-1-К в составе роботизированного комплекса [7]. Сплавление порошковых смесей происходило в присутствии постоянного магнитного поля в защитной среде из инертных газовых смесей методом лазерного спекания (рис. 1).

Мощность непрерывного лазерного излучения для наплавки порошковой смеси $\mathrm{Sm}-\mathrm{Co}$ составляла 350 Вт, для наплавки $\mathrm{Sm}-\mathrm{Fe}-$ 400 Вт. Скорость перемещения лазерного пучка в обоих случаях составляла 10 мм/с. Охлаждение сплава до комнатной температуры осу- 
ществлялось на «спокойном воздухе» в присутствии поля с магнитной индукцией 0,5 Тл в течение 30 мин.

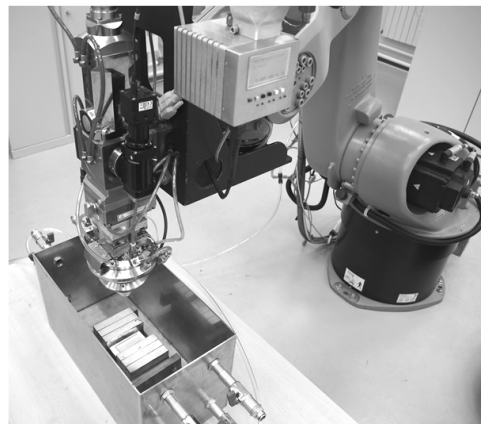

$a$

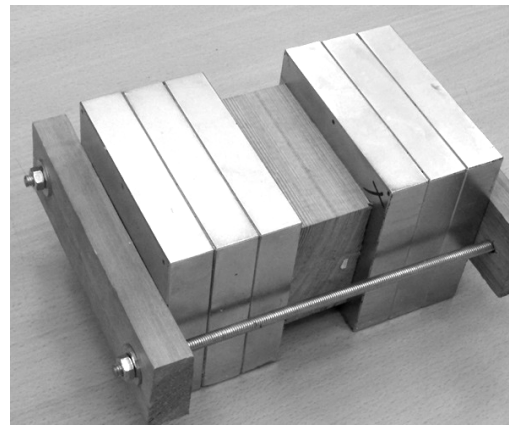

6

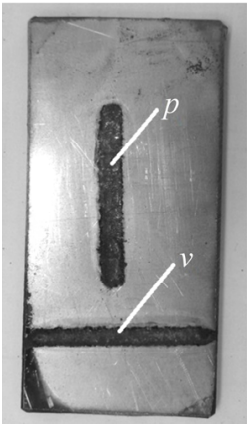

B

Рис. 1. Роботизированный лазерный комплекс для формирования покрытий из порошкового материала $\mathrm{Sm}-\mathrm{Co}(a)$, система из постоянных магнитов для создания поля с магнитной индукцией 0,5 Тл (б), внешний вид $\mathrm{Sm}-\mathrm{Co}$ и $\mathrm{Sm}-\mathrm{Fe}$ полосок, наплавленных вдоль $(v)$ и поперек (p) силовых линий внешнего постоянного магнитного поля ( 8 )

Образцы представляли собой полоски сплава Sm-Co (см. рис. 1, в), из которых были вырезаны небольшие параллелепипеды. Исследования микроструктур шлифов, приготовленных поперек и вдоль полосок (рис. 2), проводились на сканирующем зондовом микроскопе с энергодисперсионной спектрометрической приставкой (СЭМ с ЭДСП).

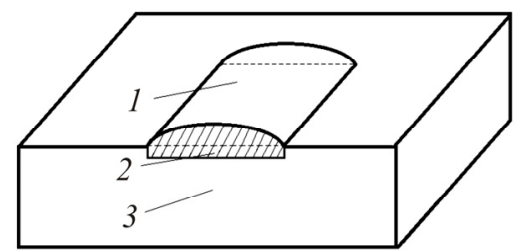

$a$

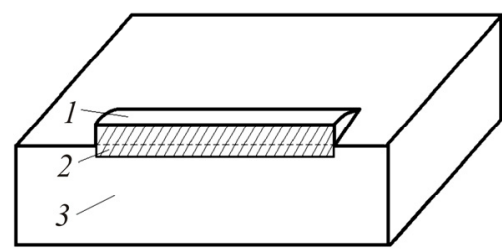

$\sigma$

Рис. 2. Графическое представление сечений в образцах: исследуемый шлиф «поперек» наплавленной полоски $(a)$ : исследуемый шлиф «вдоль» наплавленной полоски (б). 1 - наплавленный слой из порошкового материала $\mathrm{Sm}-\mathrm{Co}$ или $\mathrm{Sm}-\mathrm{Fe} ; 2$ - область сплавления $\mathrm{Sm}-\mathrm{Co}$ или $\mathrm{Sm}-\mathrm{Fe}$ с подложкой; 3 - подложка

В качестве подложек использовалась нержавеющая сталь. 


\section{1. Формирование слоев $\mathrm{Sm}-\mathrm{Co}$ лазерным излучением в постоянном магнитном поле}

Объектом исследования являлся процесс формирования слоев из порошка самария с составом rho-Sm ( 49 at. \%), hex-Sm ( 48 at. \%) и $\mathrm{Sm}_{2} \mathrm{C}_{3}(<3$ at. \%) и порошка Сo ( 99,9 at. \%), которые наплавлялись сфокусированным лазерным пучком длиной волны 1,07 мкм на подготовленные поверхности подложек. Лазерную наплавку производили в среде из инертных газовых смесей - аргона и гелия (см. рис. 1).

В процессе исследований полученного материала уделялось внимание общим снимкам всего шлифа от границы раздела между подложкой и наплавленной поверхностью, а также отдельным областям с более крупным масштабом изображения. Предельное разрешение на СЭМ-изображениях составляло 5 мкм. Методом ЭДСП в отдельных областях при крупном масштабе или в отдельных точках при максимальном разрешении оценивалась атомная и весовая концентрация элементов и определялся средний состав сплавов по выделенной площади изображения. Исследования микроструктур шлифов образцов, полученных методом лазерной наплавки в присутствии постоянного магнитного поля из составов порошковых смесей $\mathrm{Sm}_{25} \mathrm{Co}_{75}$ и $\mathrm{Sm}_{37} \mathrm{Co}_{63}$, проводились для различных вариантов их изготовления: лазерная наплавка вдоль силовых линий магнитного поля $(v)$ и лазерная наплавка поперек силовых линий постоянного магнитного поля ( $p)$. Структурное строение полученных сплавов исследовалось на шлифах, изготовленных «вдоль» наплавленной полоски (см. рис. 2, б) и «поперек» наплавленной полоски (см. рис. 2, $a$ ).

Максимальная толщина наплавленной полоски составляла около $0,7-0,8$ мм.

\section{1. Результаты исследования микроструктур из порошкового материала $\mathrm{Sm}_{25} \mathrm{Co}_{75}$}

Для исходного состава порошков $\mathrm{Sm}_{25} \mathrm{Co}_{75}$ исследованы четыре микрошлифа образцов, наплавленных поперек и вдоль силовых линий внешнего магнитного поля: S25C-p, S25C-v. Представляет интерес сравнить структуру поверхности и состав при одном направлении магнитного поля и двух срезах: поперек и вдоль наплавленной полоски. Информация о микроструктуре образца $\mathrm{Sm}_{25} \mathrm{Co}_{75}$ представлена на рис. 3. 

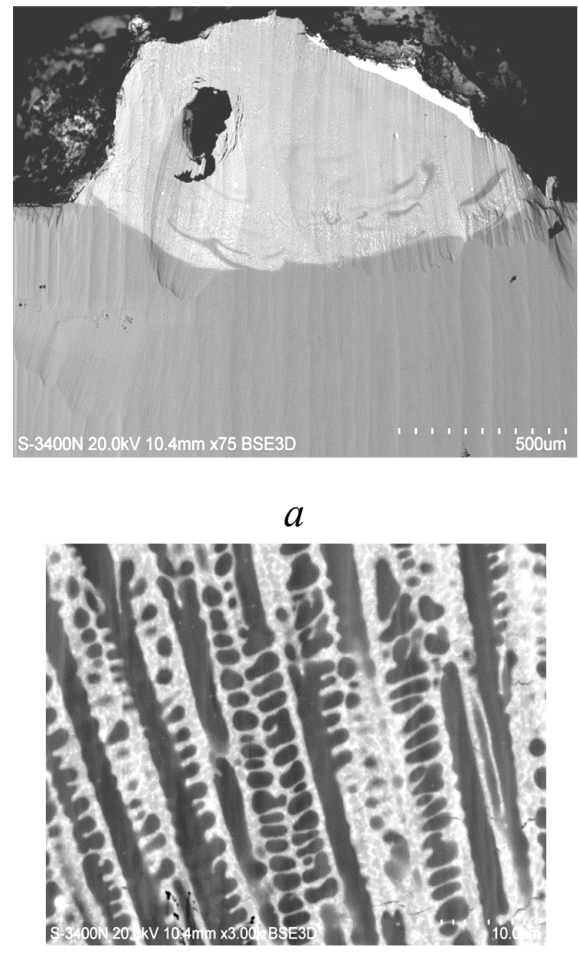

B
S25C-p(1)

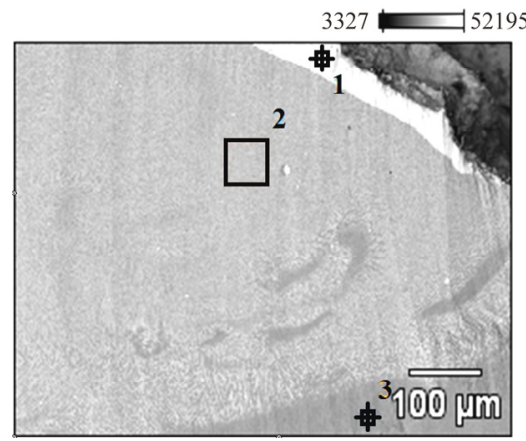

6

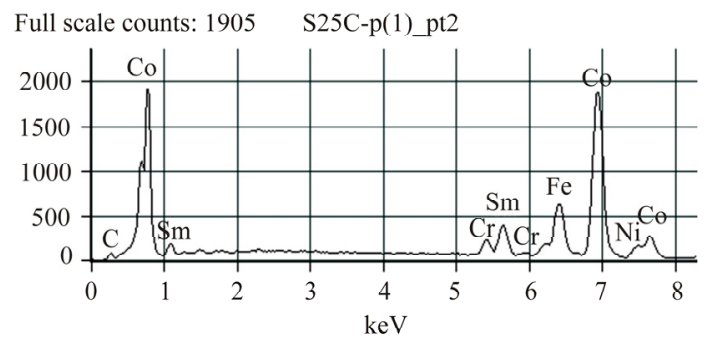

2

Рис. 3. Образец $\mathrm{S} 25 \mathrm{C}-p$ со срезом «поперек» наплавленной полоски, сформированной поперек силовых линий постоянного магнитного поля; СЭМ изображения с различным увеличением $(a, \sigma, b)$; спектр ЕДСП в точке 2 (2)

Наплавленная полоска состоит из зерен вытянутой формы, которые направлены либо перпендикулярно подложке (см. рис. 3, в), либо под небольшими углами от перпендикулярного направления. Спектры ЭДСП (см. рис. 3, г) показывают наличие различных элементов около центра полоски (точка 2) со средним составом $\mathrm{Fe}_{18.1} \mathrm{Co}_{57.6} \mathrm{Sm}_{13.9} \mathrm{Ni}_{6.2} \mathrm{Cr}_{1.9}$.

В точке 1 (см. рис. $3, \sigma$ ), присутствуют в основном два элемента $\mathrm{Sm}_{33.2} \mathrm{O}_{59.6}$, что свидетельствует о формировании оксидов самария с переменным составом. Это подтверждается данными рентгеновских исследований для образцов, полученных нами ранее методом лазерной порошковой наплавки [8]. Следовательно, в процессе остывания образца после лазерной наплавки при снижении потока смеси аргона и гелия в приповерхностной области происходит окисление самария. Наличие в центре наплавленной полоски заметных атомных процентов 
хрома, железа и никеля подтверждает их диффузионное движение из подложки в наплавляемый слой.

На шлифе того же образца S25C- $p$, но со срезом вдоль наплавленной полоски (см. рис. 2, б) обнаружена сходная структура с частичным окислением самария в приповерхностной области (рис. $4, a$ ) и усредненным составом в центре полоски $\mathrm{Fe}_{15.3} \mathrm{Co}_{63.4} \mathrm{Sm}_{8.2} \mathrm{Ni}_{3.7} \mathrm{Cr}_{1.9}$ (рис. 4 , б), который лишь незначительно различается концентрациями основных элементов Sm и Со. Следовательно, состав наплавленного слоя в данном случае слабо зависит от направления постоянного внешнего магнитного поля, присутствующего в процессе лазерной наплавки.

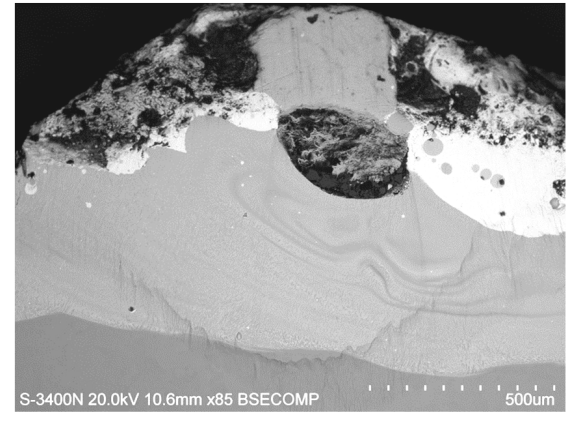

$a$

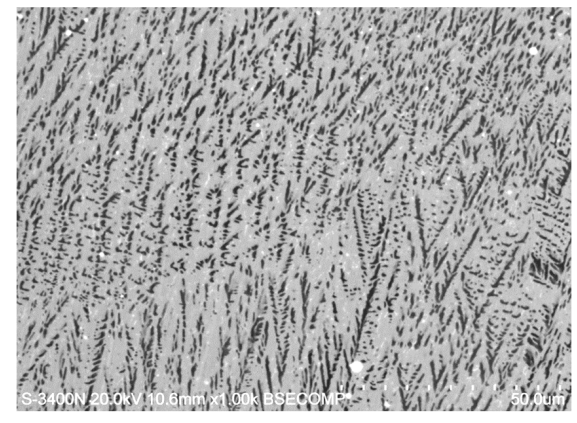

$\sigma$

Рис. 4. Образец S25C-p со срезом «вдоль» наплавленной полоски, сформированной поперек силовых линий постоянного магнитного поля; СЭМ-изображения с различным увеличением $(a, \sigma)$

В образцах S25C-v, сформированных вдоль силовых линий постоянного магнитного поля, микроструктура принципиально не изменяется. На поверхности присутствуют окислы самария, а в центре полоски наблюдается формирование разнонаправленных зерен с переменным составом, а также областей, состоящих из светлых и темных зерен (сеточной структуры). При этом состав зерен в целом более обогащен железом, хромом и никелем $\left(\mathrm{Fe}_{40.5} \mathrm{Co}_{31.3} \mathrm{Sm}_{5.0} \mathrm{Ni}_{5.8} \mathrm{Cr}_{10.7}\right)$ как вдоль, так и поперек наплавленной полоски.

\section{2. Результаты исследования микроструктур из порошкового материала $\mathrm{Sm}_{37} \mathrm{Co}_{63}$}

При увеличении доли самария в порошковой смеси $\mathrm{Sm}-\mathrm{Co}$ были сформированы две серии образцов с исходным составом: $\mathrm{Sm}_{37} \mathrm{Co}_{63}$. 
В образце, сформированном вдоль силовых линий магнитного поля $(\mathrm{S} 37 \mathrm{C}-v)$ (рис. $5, a, \sigma)$ и вырезанном «поперек» полоски (см. рис. 2, $a$ ), заметно изменяется микроструктура образца. Уменьшается плотность вытянутых зерен и появляется светлая область с небольшими вкраплениями темных зерен, обедненных самарием (по данным ЭДСП).

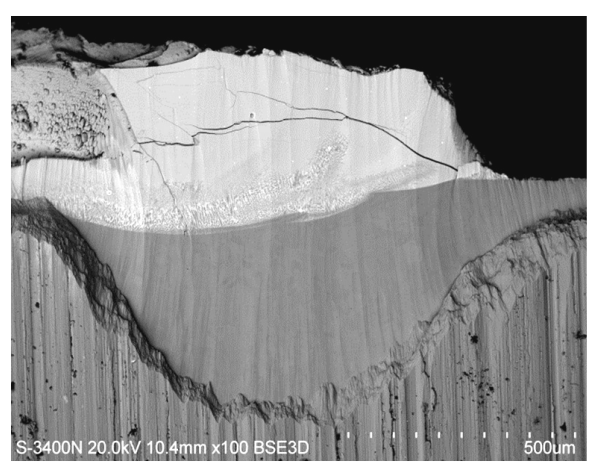

$a$

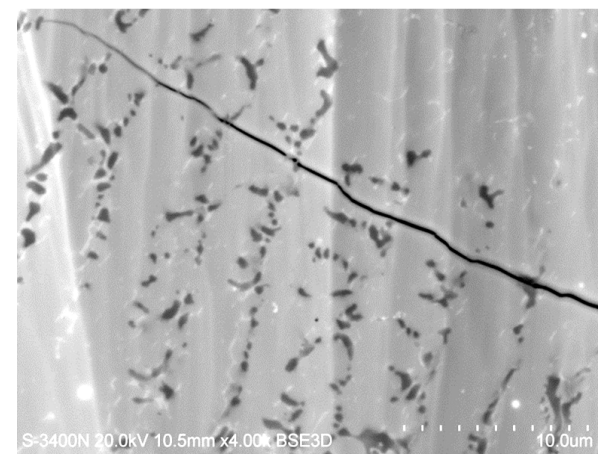

$\sigma$

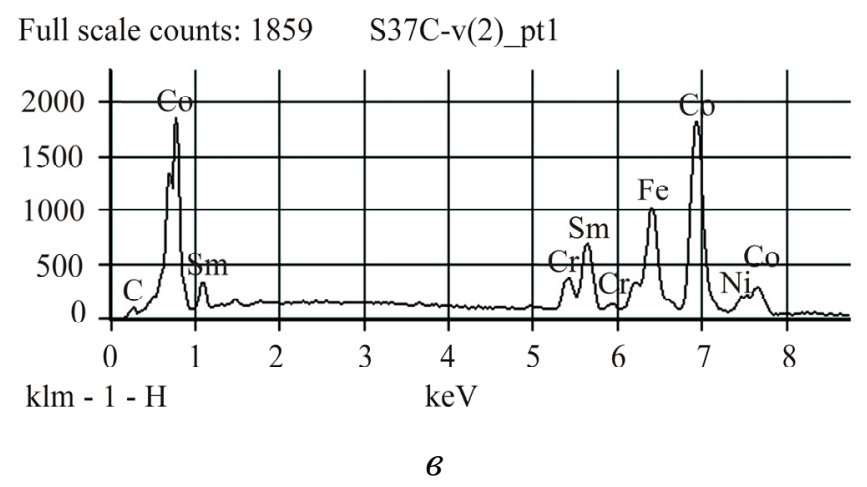

Рис. 5. Образец S37C-v со срезом «поперек» полоски, наплавленной вдоль силовых линий постоянного магнитного поля. СЭМ-изображения с различным увеличением $(a, \sigma)$; спектр ЕДСП в светлой части изображения (б), соответствующего центру полоски по высоте (в)

В центре светлой области образца $\mathrm{S} 37 \mathrm{C}-v$ (см. рис. 5, б) заметно увеличивается концентрация кобальта и самария по сравнению с образцами $\mathrm{S} 25 \mathrm{C}-p$ и $\mathrm{S} 25 \mathrm{C}-v$. Средний состав можно представить формулой: $\mathrm{Fe}_{13.5} \mathrm{Co}_{60.9} \mathrm{Sm}_{9.4} \mathrm{Ni}_{4.2} \mathrm{Cr}_{1.5} \mathrm{O}_{5.0} \mathrm{C}_{5.9}$ (рис. 5, в). Наличие кислорода и углерода в центре полоски свидетельствует о вкладе оксидов и карбидов самария, что может повлиять на магнитные свойства и коэрцитивную силу. 
Шлиф, изготовленный «вдоль» полоски в образце $\mathrm{S} 37 \mathrm{C}-v$ (рис. 6), показал чередование в центре областей, с преимущественным вкладом от светлых зон с небольшими вкраплениями темных зерен (см. рис. $6, a$ ) и чередующихся темных и светлых областей (сеточной структуры) (см. рис. 6, б).

Данные ЭДСП показали, что в первой области (см. рис. 6, a) средний состав можно описать формулой $\mathrm{Fe}_{18.0} \mathrm{Co}_{57.4} \mathrm{Sm}_{10.0} \mathrm{Ni}_{4.1} \mathrm{Cr}_{3.2}$.

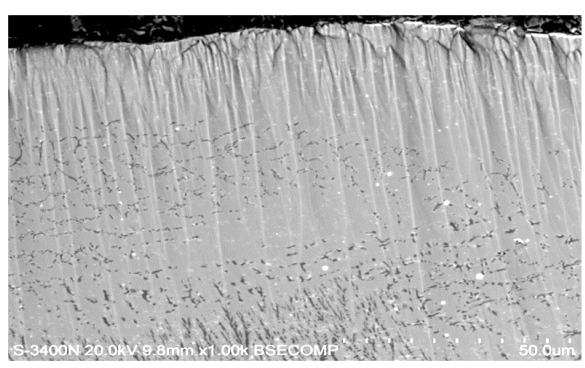

$a$

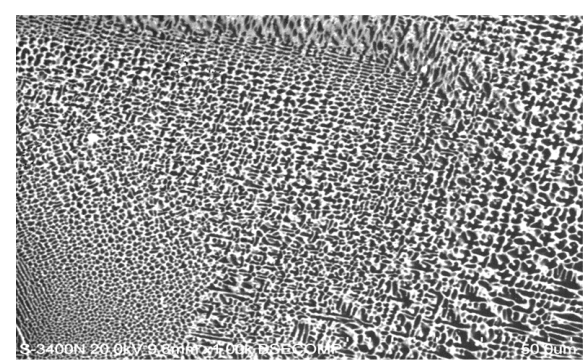

$\sigma$

Рис. 6. Образец S37C-v со срезом «вдоль» полоски, наплавленной вдоль силовых линий постоянного магнитного поля; СЭМ-изображения с различным увеличением $(a, \sigma)$

В области с сеточной микроструктурой состав несколько изменяется в сторону увеличения концентрации железа, хрома и никеля, а также - уменьшения концентрации самария и кобальта: $\mathrm{Fe}_{32.3} \mathrm{Co}_{41.4} \mathrm{Sm}_{7.5} \mathrm{Ni}_{5.5} \mathrm{Cr}_{7.5}$. Поскольку данные области распределены случайно, то это может сказаться на изменении магнитной восприимчивости и коэрцитивной силы.

В микроструктуре сплава с исходным составом $\mathrm{Sm}_{37} \mathrm{Co}_{63}$, сформированным поперек силовых линий постоянного магнитного поля, рассмотрим поперечный срез полоски $\mathrm{S} 3 \mathrm{C}-p$ (рис. 7). В нижней части полоски (см. рис. 7, $a$ ) имеется область со сложным пересечением разнонаправленных зерен с различным цветом и, соответственно, различной концентрацией в них самария.

Верхняя часть полоски более обогащена самарием и имеет светлый и почти однородный тон (см. рис. 7, $a$ ). Средний состав в светлой области описывается формулой $\mathrm{Fe}_{21.7} \mathrm{Co}_{52.4} \mathrm{Sm}_{10.2} \mathrm{Ni}_{4.0} \mathrm{Cr}_{4}$ (см. рис. 7, в). В верхней левой части рис. 7, $a$ присутствует светлая область, которая состоит почти полностью из оксида самария и имеет средний состав: $\mathrm{Sm}_{34.7} \mathrm{O}_{58.6}$. 


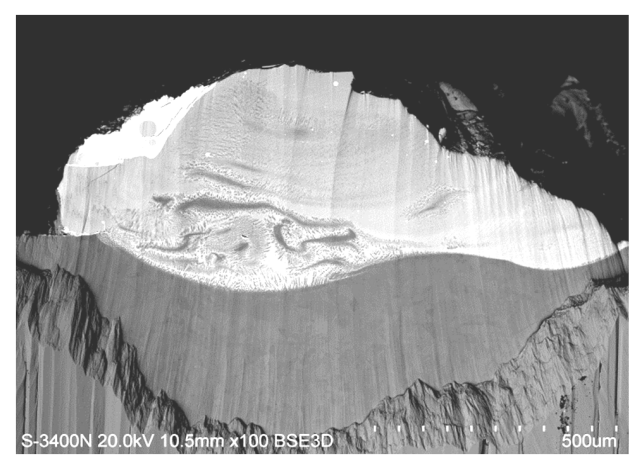

$a$

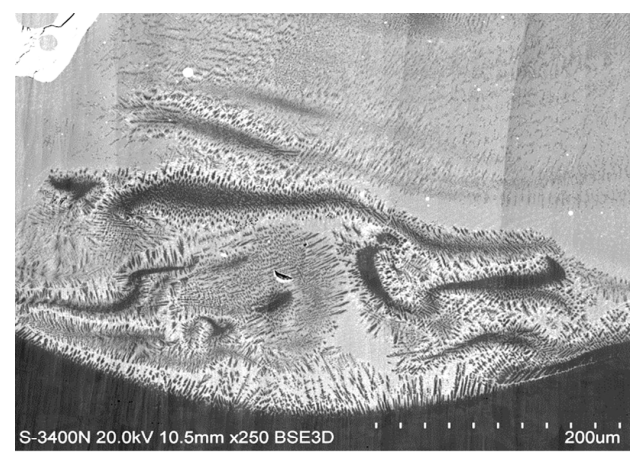

6

Full scale counts: $1865 \quad$ S37C-p(3)_pt1

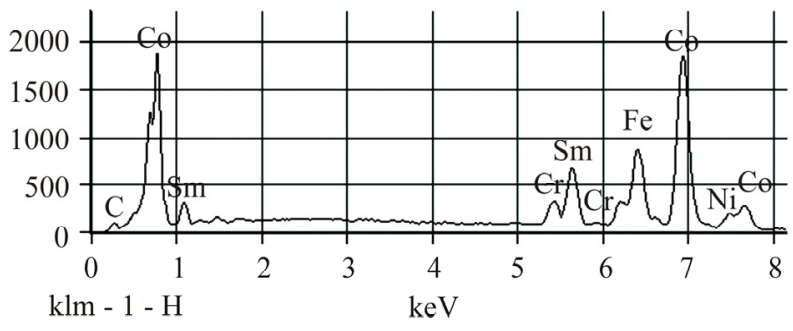

B

Рис. 7. Образец S37C-p со срезом «поперек» полоски, наплавленной поперек силовых линий постоянного магнитного поля; СЭМ-изображения с различным увеличением $(a, \sigma)$; спектр ЕДСП в правом верхнем углу изображения (б), соответствующего центру полоски по высоте (в)

Анализ микроструктуры образца S37C-p, с подготовленным продольным срезом (магнитное поле было направлено перпендикулярно к данному срезу) показал, что в перпендикулярном магнитном поле вдоль полоски облегчено образование сеточной структуры. Ее формирование приводит к заметному увеличению средней концентрации железа, хрома и никеля, поступающих из подложки, и снижению концентрации самария и кобальта. Средний состав можно описать формулой $\mathrm{Fe}_{39.8} \mathrm{Co}_{33.8} \mathrm{Cr}_{10.1} \mathrm{Sm}_{4.0} \mathrm{Ni}_{5.6}$. Сравнивая микроструктуру с образцом, полученным путем лазерной наплавки вдоль силовых линий постоянного магнитного поля (см. рис. 5), следует заметить, что растворение самария в центре полоски в среднем увеличивается.

При уменьшении концентрации самария в порошковой смеси после лазерной наплавки сетчатая структура не наблюдается в условиях присутствия продольного или поперечного магнитного поля. 
Вместе с тем при увеличении концентрации самария наблюдаются его преимущественная сегрегация в приповерхностной области и усиленное окисление с формированием оксидов и карбидов самария. Следовательно, в этом случае уменьшается растворимость самария в сплаве кобальта с железом, никелем и хромом и наблюдается его выталкивание на поверхность, что коррелирует с данными первых экспериментов с системой Sm-Co на подложках из нержавеющей стали и другим способом подачи порошков [7].

\section{2. Формирование слоев $\mathrm{Sm}-\mathrm{Fe}$ лазерным излучением в постоянном магнитном поле}

Для оценки микроструктуры сплавов с исходным составом $\mathrm{Sm}-\mathrm{Fe}$, полученных методом лазерной наплавки на подложке из нержавеющей стали в присутствии внешнего постоянного магнитного поля, использовались смеси порошков самария и железа. Исследования проводились для двух вариантов: $\mathrm{Sm}_{20} \mathrm{Fe}_{80}$ и $\mathrm{Sm}_{37} \mathrm{Fe}_{63}$.

Образцы сплавов изготавливались в виде коротких полосок (см. рис. 1, в). Исследования структуры сплава проводились на поперечных и продольных срезах (см. рис. 2) для двух направлений внешнего поля с магнитной индукцией 0,5 Тл: вдоль и поперек силовых линий постоянного магнитного поля.

\section{1. Результаты исследования микроструктур из порошкового материала $\mathrm{Sm}_{20} \mathrm{Fe}_{80}$}

На поперечном срезе образца $\mathrm{Sm}_{20} \mathrm{Fe}_{80}(\mathrm{~S} 20 \mathrm{~F}-v)$, полученного методом лазерной наплавки в условиях внешнего магнитного поля, направленного вдоль полоски (рис. 8), видны неоднородности распределения самария по поверхности шлифа (см. рис. $8, a$ ). Однако на поверхности полоски отсутствует сегрегировавший самарий. Толщина слоя наплавленного материала не превышает 0,25 мм.

Микроструктура сформирована зернами с различным направлением и формой: от продолговатой до округлой формы с размерами в единицы микрон, которые объединены в крупные блоки и имеют выраженные границы в виде микротрещин (см. рис. 8, б). Средний состав в полоске можно описать формулой $\mathrm{Fe}_{71.4} \mathrm{Cr}_{8.8} \mathrm{Sm}_{6.4} \mathrm{Ni}_{3.2}$.

В белых полосах (см. рис. 8, б) наблюдается повышение концентрации самария до 10-15 ат. \%. В переходной области от подложки 
к слою покрытия наблюдается сетчатая структура, в темных областях которой отсутствует самарий, а в светлых областях его концентрация составляет до 10 ат. \%. Это соответствует сегрегации самария на границах зерен сплава с составом $\mathrm{Fe}_{77.3} \mathrm{Cr}_{12.7} \mathrm{Ni}_{4.7}$.

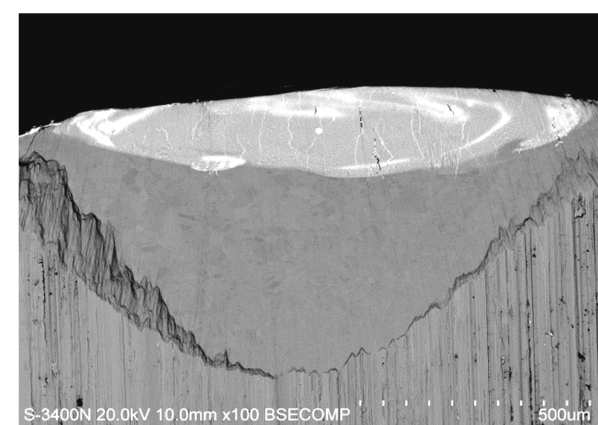

$a$

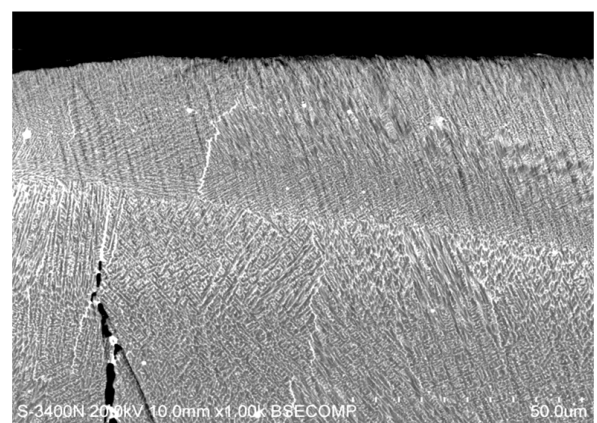

$\sigma$

Full scale counts: $1965 \quad$ S20F-v(1) pt2

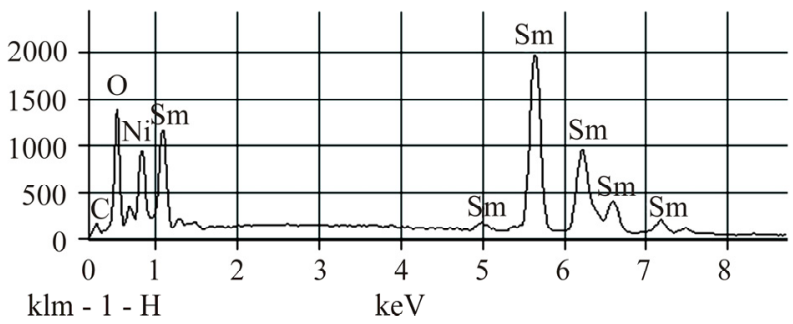

B

Рис. 8. Образец S20F-v со срезом «поперек» наплавленной полоски, наплавленной вдоль силовых линий постоянного магнитного поля; СЭМ-изображения с различным увеличением $(a, \sigma)$; спектр ЕДСП в правом верхнем углу изображения $(\sigma)$, соответствующего центру полоски по высоте (в)

Изменение направления среза и подготовка шлифа вдоль полоски и приложенного при наплавке магнитного поля (рис. 9) не показало существенных изменений в микроструктуре поверхности шлифа.

На поверхности шлифа наблюдаются микротрещины и отдельные области, обогащенные самарием. При увеличении разрешения (см. рис. 9, б) становятся хорошо видны границы между блоками с различной микроструктурой зерен внутри блоков. Они изменяют свою форму и направление, что свидетельствует о незначительном влиянии на формирование микроструктуры внешнего магнитного поля. Концентрация самария еще недостаточно велика, поэтому сегрегация са- 
мария наблюдается в основном на границах микрозерен с пониженной, но не нулевой концентрацией самария в них. Средний состав в центре полоски описывается формулой $\mathrm{Fe}_{76.4} \mathrm{Cr}_{7.2} \mathrm{Sm}_{7.2} \mathrm{Ni}_{2.6}$.

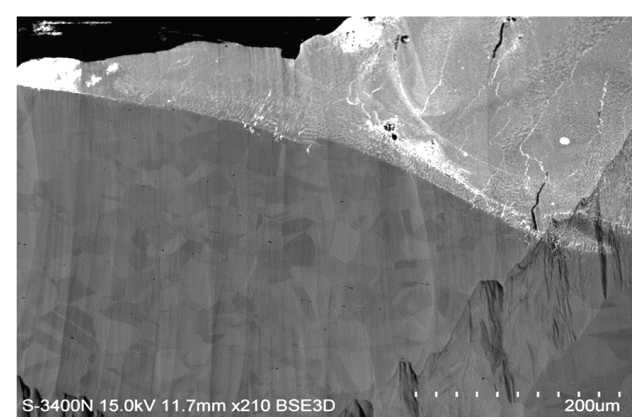

$a$

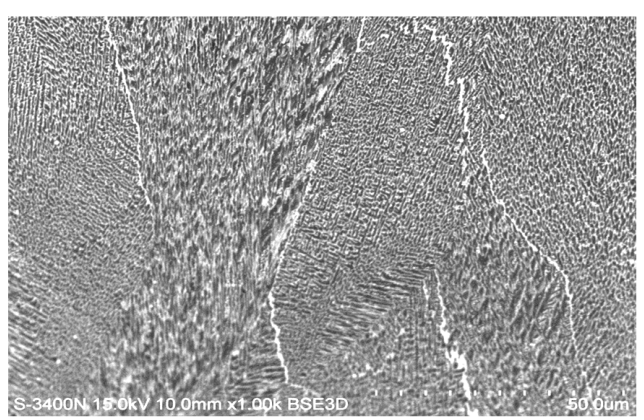

$\sigma$

Рис. 9. Образец S20F-v со срезом «вдоль» наплавленной полоски, наплавленной вдоль силовых линий постоянного магнитного поля; СЭМ-изображения с различным увеличением $(a, \sigma)$

При большом увеличении методом ЭДСП удается измерить состав зерен и границ раздела: $\mathrm{Fe}_{82.1} \mathrm{Cr}_{7.55} \mathrm{Sm}_{4.0} \mathrm{Ni}_{1.7}$ (в зернах) и $\mathrm{Fe}_{56.1} \mathrm{Cr}_{5.5} \mathrm{Sm}_{15.7} \mathrm{Ni}_{3.8}$ (на границах раздела). Следовательно, самарий растворяется на уровне микроструктуры сформированного покрытия и в основном на границах микрозерен. Термические напряжения снимаются за счет введения микротрещин.

В образцах, полученных при лазерной наплавке в условиях воздействия постоянного магнитного поля, направленного поперек полосок наплавки (S20F-p), также рассматривались два образца, вырезанные поперек и вдоль полосок.

На рис. 10 представлен микрошлиф, изготовленный «поперек» полоски, наплавленной поперек силовых линий постоянного магнитного поля.

Видно, что толщина наплавленной полоски не превышала 0,3 мм, а на поверхности отсутствовал сегрегировавший самарий. При большем увеличении стало видно (см. рис. 10, б), что микроструктура состоит из крупных блоков, которые составлены из разно направленных микрозерен с размерами в единицы микрон. Средний состав в центре полоски по данным ЭДСП составил $\mathrm{Fe}_{76.9} \mathrm{Cr}_{2.2} \mathrm{Sm}_{10.6} \mathrm{Ni}_{0.8}$. Состав зерен и границ раздела определен следующим: $\mathrm{Fe}_{87} \mathrm{Cr}_{2.9} \mathrm{Sm}_{4.9}$ (в зернах) и $\mathrm{Fe}_{61.3} \mathrm{Cr}_{5.3} \mathrm{Sm}_{19.8}$ (на границах раздела). 


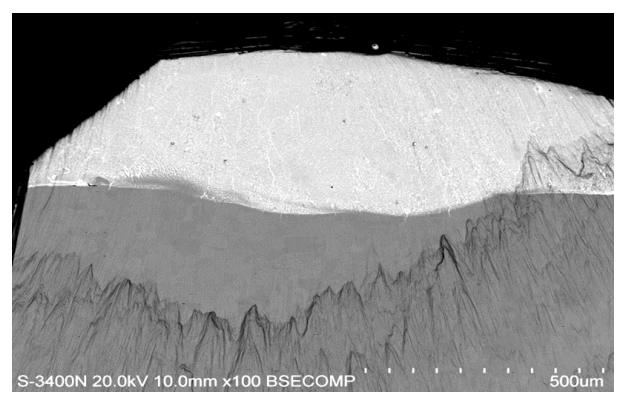

$a$

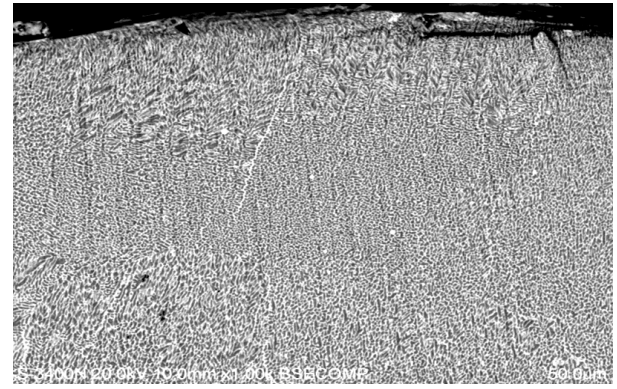

$\sigma$

Full scale counts: $2003 \quad$ S20F-p(1)_pt2

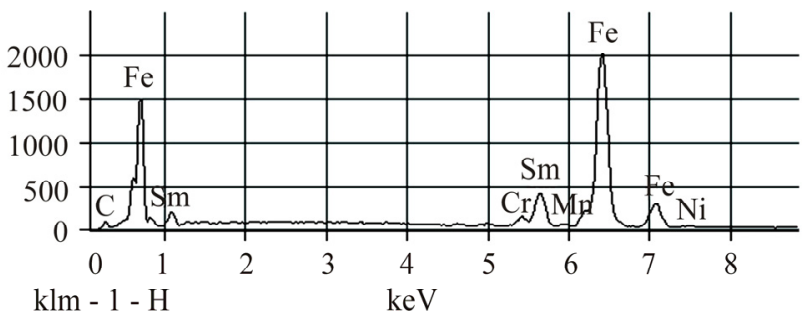

B

Рис. 10. Образец S20F-p со срезом «поперек» наплавленной полоски (наплавленной поперек силовых линий постоянного магнитного поля); СЭМ-изображения с различным увеличением $(a, \sigma)$; спектр ЕДСП в правом верхнем углу изображения $(\sigma)$, соответствующего центру полоски по высоте (в)

При рассмотрении шлифа вдоль полоски в образце $\mathrm{Sm} 20 \mathrm{Fe}-p$ (рис. $11, a$ ) обнаружена достаточно однородная структура в центре полоски.

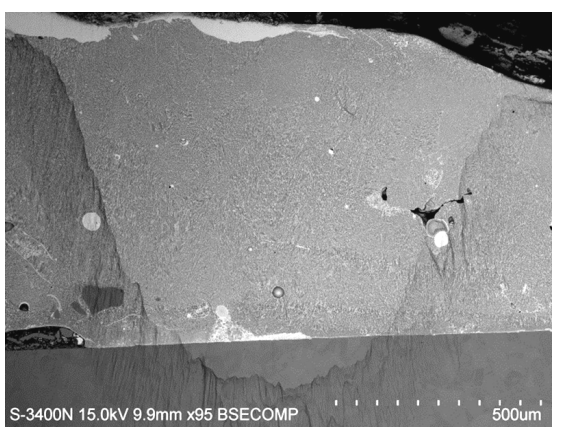

$a$

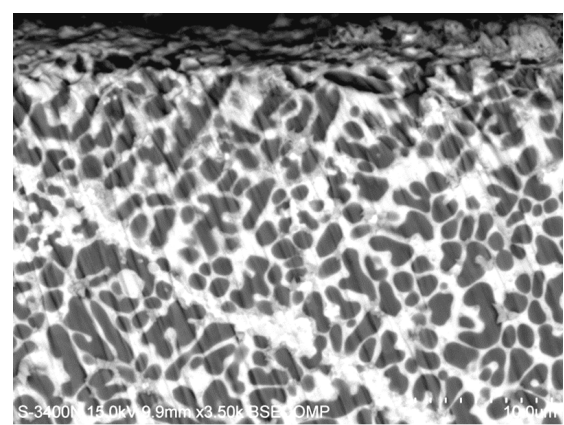

б

Рис. 11. Образец $\mathrm{S} 20 \mathrm{~F}-p$ со срезом «вдоль» наплавленной полоски (наплавленной поперек силовых линий постоянного магнитного поля); СЭМ-изображения с различным увеличением $(a, \sigma)$ 
В отдельных местах наблюдаются макропоры с размерами 20-50 мкм, что может быть связано с возникновением около границы раздела структурных неоднородностей с различной температурой затвердевания из жидкой фазы. На изображении с большим увеличением (рис. 11, б) видно, что образуется сетчатая структура с заметным вкладом от областей белого цвета, которые обогащены самарием. Средний состав сплава в центре полоски можно описать формулой: $\mathrm{Fe}_{74.1} \mathrm{Sm}_{11.95} \mathrm{O}_{6.5} \mathrm{C}_{7.5}$.

Сравнение со шлифом данного образца, сделанного в другой плоскости, показывает существенные неоднородности по составу, что свидетельствует о влиянии среды из смеси инертных газов на процесс затвердевания сплава.

\section{2. Результаты исследования микроструктур из порошкового материала $\mathrm{Sm}_{37} \mathrm{Fe}_{63}$}

Исследования влияния увеличения концентрации самария и уменьшения концентрации железа в сплавах $\mathrm{Sm}_{37} \mathrm{Fe}_{63}$, полученных методом лазерной наплавки, проводились для двух вариантов направлений внешнего магнитного поля и двух способов изготовления шлифов (см. рис. 2): образцы S37F-v и S37F-p. Образец S37F-v сформирован в продольном (по полоске) магнитном поле (рис. 12). Толщина наплавленного слоя не превышает 0,2 мм.

Он имеет достаточно однородную структуру, некоторую плотность микротрещин между блоками и неровную границу раздела. При большем увеличении (см. рис. 12, б) видно, что микроструктура сформирована в виде сетки чередующихся темных микрокристаллов с размерами в единицы микрон и границ раздела между ними, которые обогащены самарием. Средний состав в центре наплавленной полоски характеризуется формулой $\mathrm{Fe}_{74.3} \mathrm{Cr}_{6.3} \mathrm{Sm}_{9.0} \mathrm{Ni}_{2.5}$. При этом в нижней части полоски состав остается без заметных изменений, что свидетельствует о достаточно однородной наплавке и затвердевании (кристаллизации). Присутствие атомов никеля и хрома подтверждает усиленную диффузию этих атомов, а также атомов железа, из подложки вплоть до поверхности наплавленной полоски. На шлифе, изготовленном вдоль полоски, и при внешнем продольном магнитном поле (рис. 13, $a$ ) наблюдается микроструктура с микротрещинами, разно направленными микрокристаллами и частичной сегрегацией самария на поверхности полосок. 


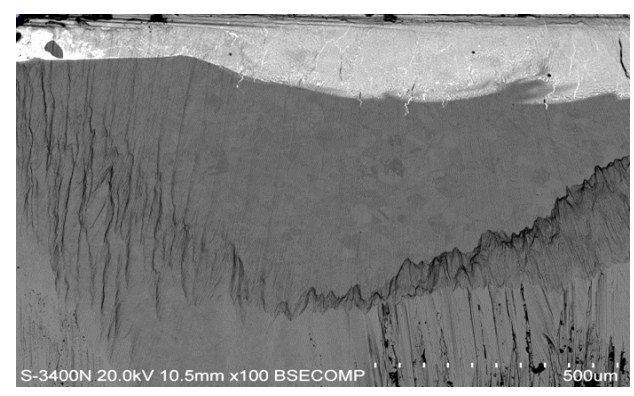

$a$

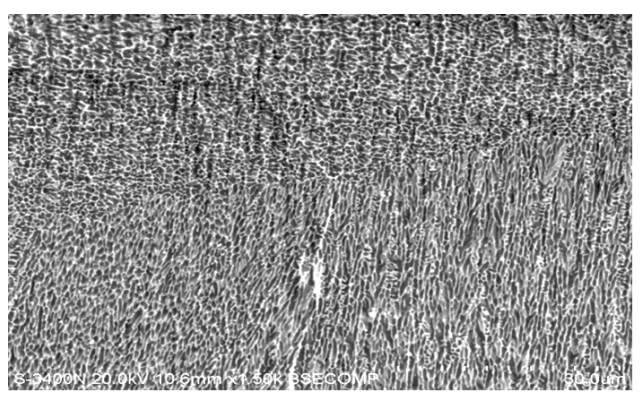

$\sigma$

Full scale counts: $1951 \quad$ S37F-v(2)_pt2

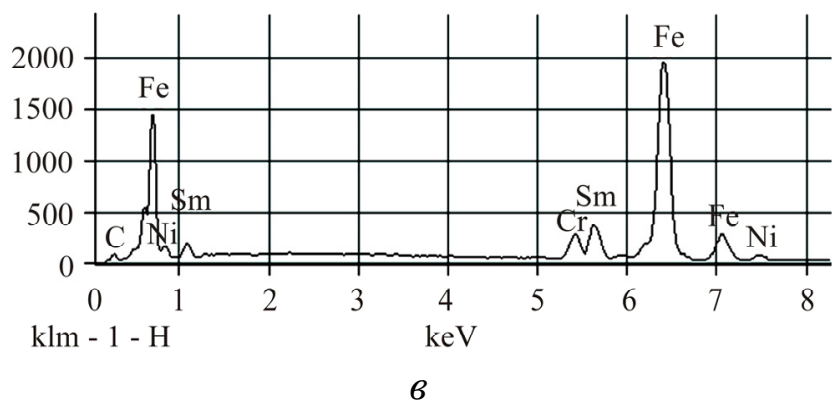

Рис. 12. Образец S37F-v со срезом «поперек» наплавленной полоски (наплавленной вдоль силовых линий постоянного магнитного поля); СЭМ-изображения с различным увеличением $(a, \sigma)$; спектр ЕДСП в правом верхнем углу изображения (б), соответствующего центру полоски по высоте (в)

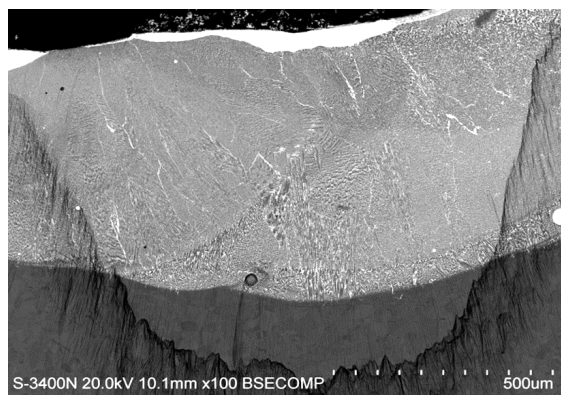

$a$

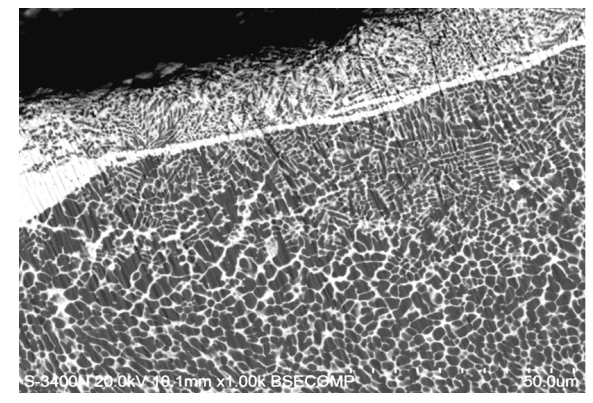

$\sigma$

Рис. 13. Образец S37F-v со срезом «вдоль» наплавленной полоски (наплавленной вдоль силовых линий постоянного магнитного поля); СЭМ-изображения с различным увеличением $(a, \sigma)$

Граница раздела с подложкой имеет неровности и отдельные вкрапления или макропоры. В приповерхностной области (см. рис. 13, б) наблюдается сеточная структура. 
Размеры микрозерен изменяются от единиц примерно до 5 микрон. Данные ЭДСП показывают в центре полоски состав $\mathrm{Fe}_{74.1} \mathrm{Cr}_{6.7} \mathrm{Sm}_{7.9} \mathrm{Ni}_{2.5} \mathrm{C}_{8.8}$. При большем увеличении удалось измерить состав в областях темного $\left(\mathrm{Fe}_{78.8} \mathrm{Cr}_{11.4} \mathrm{Sm}_{3.7} \mathrm{Ni}_{2.3} \mathrm{C}_{3.8}\right)$ и светлого $\left(\mathrm{Fe}_{50.2} \mathrm{Cr}_{7.3} \mathrm{Sm}_{19.7} \mathrm{Ni}_{7.6} \mathrm{C}_{13.9}\right)$ цветов. Наличие углерода в заметной концентрации в темных и светлых областях сеточной структуры свидетельствует о карбидизации сплава при затвердевании.

Анализ поперечного (рис. 14) и продольного (см. рис. 13) шлифов для сплава с составом смеси $\mathrm{Sm}_{37} \mathrm{Fe}_{63}$ показывает, что сеточная структура сохраняется в обоих случаях. Однако при этом появляются крупные неоднородности вблизи границы раздела с подложкой.
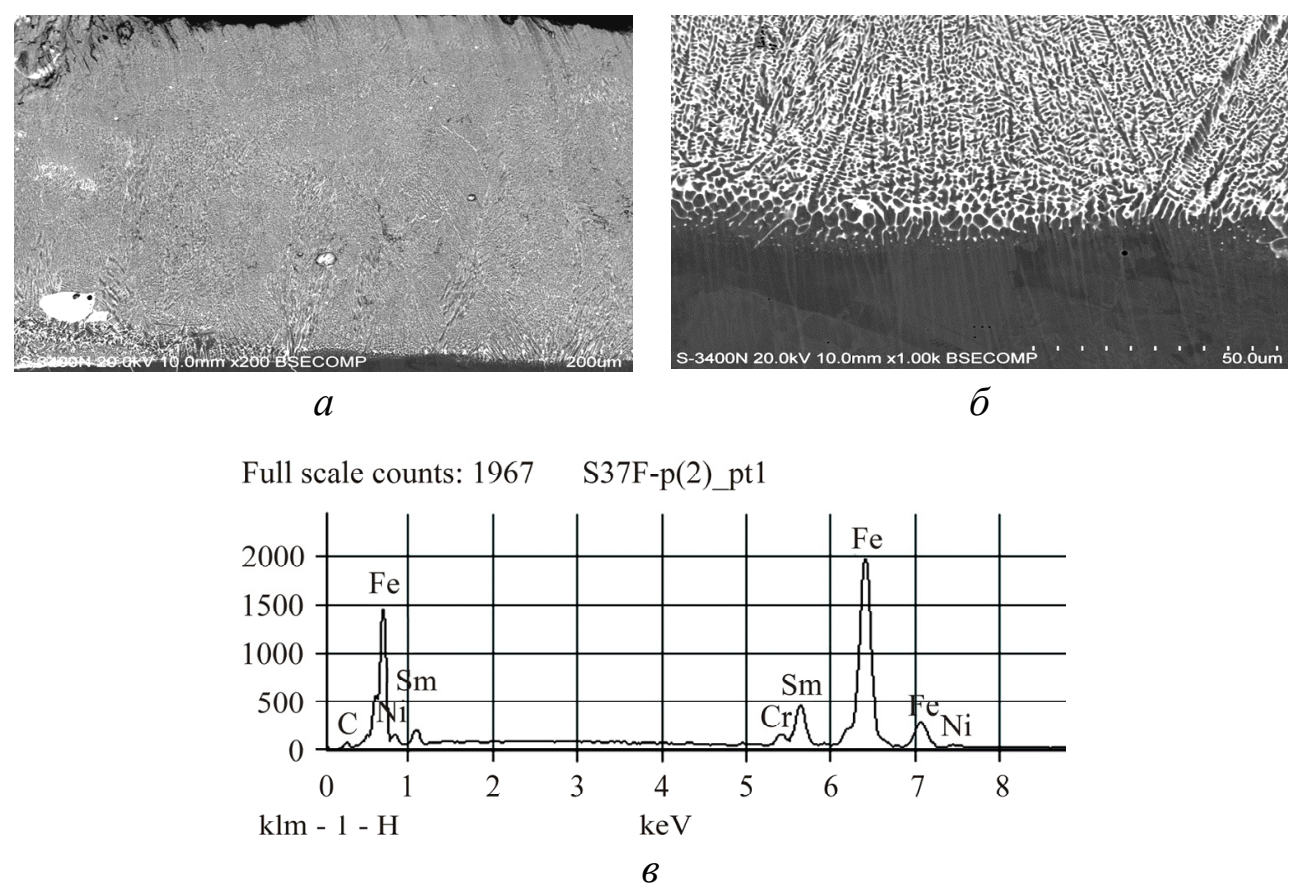

Рис. 14. Образец S37F-p со срезом «поперек» наплавленной полоски (наплавленной поперек силовых линий постоянного магнитного поля); СЭМ-изображения с различным увеличением $(a, \sigma)$; спектр ЕДСП в правом верхнем углу изображения (б), соответствующего центру полоски по высоте (в)

Средний состав сплавов в обоих срезах можно описать формулой $\mathrm{Fe}_{77.0} \mathrm{Cr}_{3.1} \mathrm{Sm}_{11.4} \mathrm{Ni}_{1.1}$ (см. рис. 14, в). Неоднородности имеют состав, определяемый оксидами самария. Более тонкая микроструктура показана на рис. 14,6 . Она состоит, как и для других образцов, из чередования 
темных микрокристаллов со светлой границей раздела между ними. Состав темных областей описывается формулой $\mathrm{Fe}_{74.8} \mathrm{Sm}_{10.8} \mathrm{Cr}_{3.8} \mathrm{Ni}_{1.8}$. В светлых границах наблюдается появление заметной концентрации углерода: $\mathrm{Fe}_{53.4} \mathrm{Sm}_{21.3} \mathrm{C}_{16.7} \mathrm{Cr}_{4.6} \mathrm{Ni}_{2.3}$.

\section{Заключение}

В процессе исследований ферромагнитных $\mathrm{Sm}-\mathrm{Co}$ и $\mathrm{Sm}-\mathrm{Fe}$ покрытий полученных на немагнитных подложках с использованием энергии непрерывного лазерного излучения, в присутствии поля с магнитной индукцией 0,5 Тл, в защитной среде из инертных газовых смесей, изучено влияние внешнего постоянного магнитного поля на формирование систем Sm-Co и $\mathrm{Sm}-\mathrm{Fe}$ с различной концентрацией самария, кобальта и железа. Разработана методика лазерной порошковой наплавки металлических порошков самария и кобальта. Изготовлена оснастка для создания внешнего постоянного магнитного поля в зоне лазерной наплавки. После формирования локальных зон намагниченности магнитожестких материалов $\mathrm{Sm}-\mathrm{Co}$ и $\mathrm{Sm}-\mathrm{Fe}$ с различным процентным соотношением в виде двумерных и трехмерных массивов в присутствии внешнего магнитного поля определены их морфология и кристаллическая структура. Перемешивание расплава материалов $\mathrm{Sm}-\mathrm{Fe}$ под воздействием лазерного излучения и кристаллизация отдельных зерен в матрице $\mathrm{Sm}$ с образованием сетчатой структуры в присутствии внешнего магнитного поля происходят значительно лучше, чем при его отсутствии [9]. Исследована структурная неоднородность на границе раздела подложки и слоя твердого раствора.

Исследование, кроме подразд. 2.1, выполнено за счет гранта Российского научного фонда (проект № 15-12-00032) «Изучение механизмов формирования локальных зон заданной конфигурации, обладаюших магнитными свойствами, в процессе сплавления частиц на металлической подложке при воздействии лазерного излучения».

Работа, описанная в подразд. 2.1, выполнена при финансовой поддержке Министерства образования и науки Российской Федерации (постановление П218, договор № 02.G25.31.0116 om 14.08.2014 2. между ОАО «Центр судоремонта «Дальзавод» и Министерством образования и науки Российской Федерацчии). 


\section{Список литературы}

1. Benaissa M., Krishnan Kannan M., Fullerton E.E. Magnetic anisotropy and its microstructural origin in epitaxially grown bicrystal Sm-Co thin films // IEEE Transactions on Magnetics. - 1998. - № 34. - C. 12041206.

2. Magnetic hardening in $\mathrm{SmCo}_{\mathrm{x}}$-Co multilayers and nanocomposites / J.P. Liu, Y. Liu, R. Skomski, D.J. Sellmyer // Journal of Applied Physics. 1999. - № 85. - P. 4812-4814.

3. Seifert M., Neu V., Schultz L. Epitaxial thin SmCo5 films with perpendicular anisotropy // Applied Physics Letters. - 2009. - T. 94, № 2. P. 022501.

4. Nanoscale Magnetic Materials and Application / J.P. Liu, E. Fullerton, O. Gutfleisch, D.J. Sellmyer // Springer. - 2009. - 719 p.

5. Atomic structure and domain wall pinning in samarium-cobaltbased permanent magnets / M. Duerrschnabel, M. Yi, K. Uestuener, M. Liesegang, M. Katter, H.-J. Kleebe, B. Xu, O. Gutfleisch, L. MolinaLuna // Nature communications. DOI: 10.1038 / s41467-017-00059-9

6. Dudko O.V., Polonik M.V., Yatsko D.S. Optimization of the fiber laser parameters for local high-temperature impact on metal // Proceedings of SPIE (Asia-Pacific Conference on Fundamental Problems of Opto- and Microelectronics). - 2016. - Vol. 10176. - P. 1017624.

7. On the Principles of the Additive Technology Implementation of Composite Magnetic Coating's Formation on Non-Magnetic Substrates by Laser Welding of Micro Powders / Y.N. Kulchin, N.G. Galkin, E.P. Subbotin, V.M. Dolgorook, D.S. Yatsko // Solid State Phenomena. - 2015. Vol. 245. - P. 230-237.

8. Structure and magnetic properties of alloys formed by the laser welding of $\mathrm{Sm}$ and Co powders on different substrates / N.G. Galkin, Y.N. Kulchin, E.P. Suddotin, M.E. Stebliy, A.I. Nikitin, D.S. Yatsko, A.A. Kostyanko // Proceedings of SPIE. - 2017. - Vol. 10176. - 1017621.

9. Direct laser welding of Sm and Fe powders for creation of magnetic alloys on the stainless steel substrate: microstructure and magnetic structure / N.G. Galkin, Y.N. Kulchin, E.P. Subbotin, A.I. Nikitin, D.S. Yatsko, A.A. Kostyanko, D.S. Pivovarov // Proceedings of SPIE. Asia-Pacific Conference on Fundamental Problems of Opto- and Microelectronics. - 2016. Vol. 10176. - P. 1017620. DOI: 10.1117/12.2268255 


\section{References}

1. Benaissa M., Krishnan K.M., Fullerton E.E. Magnetic anisotropy and its microstructural origin in epitaxially grown bicrystal Sm-Co thin films. IEEE Transactions on Magnetics, 1998, no. 34, pp. 1204-1206.

2. Liu J.P., Liu Y., Skomski R., Sellmyer D.J. Magnetic hardening in $\mathrm{SmCo}_{\mathrm{x}}$-Co multilayers and nanocomposites. Journal of Applied Physics, 1999, no. 85, pp. 4812-4814.

3. Seifert M., Neu V., Schultz L. Epitaxial thin SmCo5 films with perpendicular anisotropy. Applied Physics Letters, 2009, vol. 94, no. 2, pp. 022501.

4. Liu J.P., Fullerton E., Gutfleisch O., Sellmyer D.J. Nanoscale magnetic materials and application. Springer, 2009, 719 p.

5. Duerrschnabel M., Yi M., Uestuener K., Liesegang M., Katter M., Kleebe H.-J., Xu B., Gutfleisch O., Molina-Luna L. Atomic structure and domain wall pinning in samarium-cobalt-based permanent magnets. Nature communications. DOI: 10.1038 / s41467-017-00059-9

6. Dudko O.V., Polonik M.V., Yatsko D.S. Optimization of the fiber laser parameters for local high-temperature impact on metal. Proceedings of SPIE (Asia-Pacific Conference on Fundamental Problems of Opto- and Microelectronics), 2016, vol. 10176, pp. 1017624.

7. Kulchin Y.N., Galkin N.G., Subbotin E.P., Dolgorook V.M., Yatsko D.S. On the principles of the additive technology implementation of composite magnetic coating's formation on non-magnetic substrates by laser welding of micro powders. Solid State Phenomena, 2015, vol. 245, pp. 230-237.

8. Galkin N.G., Kulchin Y.N., Suddotin E.P., Stebliy M.E., Nikitin A.I., Yatsko D.S., Kostyanko A.A. Structure and magnetic properties of alloys formed by the laser welding of Sm and Co powders on different substrates. Proceedings of SPIE, 2017, vol. 10176, pp. 1017621.

9. Galkin N.G., Kulchin Y.N., Subbotin E.P., Nikitin A.I., Yatsko D.S., Kostyanko A.A., Pivovarov D.S. Direct laser welding of Sm and Fe powders for creation of magnetic alloys on the stainless steel substrate: microstructure and magnetic structure. Proceedings of SPIE. Asia-Pacific Conference on Fundamental Problems of Opto- and Microelectronics, 2016, vol. 10176, pp. 1017620. DOI: 10.1117/12.2268255

Получено 23.09.2018 